\title{
Características vegetativas e de frutos de mamoeiros obtidos por seleção massal
}

\section{Vegetative and fruit characteristics of papaya trees obtained by mass selection}

\author{
Mariela Mattos da Silva ${ }^{*}$; Sabrina Garcia Broetto ${ }^{2}$; Sigrid Costa Valbão; \\ Adelaide de Fátima Santana da $\operatorname{Costa}^{4}$; Diolina Moura Silva ${ }^{5 *}$
}

\section{Resumo}

O presente trabalho teve como objetivo monitorar características vegetativas e dos frutos de mamoeiro (Carica papaya L.), obtidos por seleção massal de plantas da cv. Golden, nos primeiros meses de produção. As amostragens foram realizadas em uma lavoura comercial aos $0,20,40,70,130,180$, 230, 260, 280, 310 e 340 dias após o plantio (DAP) e os primeiros frutos foram colhidos 230 DAP. Os resultados obtidos evidenciaram baixa altura das plantas (199 $\mathrm{cm}$ em 340 DAP) e baixa altura da primeira floração $(71 \mathrm{~cm})$, aspectos que facilitam a colheita. As plantas apresentaram boa produtividade, com elevado número de folhas (ampla área de recobrimento dos frutos) e cerca de 60 frutos por planta. Os frutos mantiveram características semelhantes aos da cv. Golden. A massa fresca dos frutos variou de 302,4 a $467,5 \mathrm{~g}$, encontrando-se dentro da faixa recomendada para comércio interno. A média da espessura da polpa foi de $2,3 \mathrm{~cm}$, atributo de grande interesse econômico. A firmeza da polpa mostrou uma estreita relação com os fatores climáticos, onde grandes variações de temperatura e pluviosidade aceleraram a perda de firmeza.

Palavras-chave: Carica papaya L., melhoramento, qualidade do fruto

\begin{abstract}
The present work had as purpose to evaluate some characteristics of papaya trees (Carica papaya L.), Golden cultivar, obtained trough plant mass selection, regarding plant and fruit quality in the first months of production. The samples were evaluated in a commercial crop at: $0,20,40,70,130,180$, 230, 260, 280, 310 and 340 days after the planting (DAP) and the first fruits were harvested at 230 DAP. The results showed the low height $(199 \mathrm{~cm}$ in 340 DAP) and low first flowering's heigth $(71 \mathrm{~cm})$, which is important to facilitate the harvest process. The plants presented good yield with high number of leafs (allowing a great area of fruit cover) and about 60 fruits per plant. The fruits kept similar features to cv. Golden. The fruit's fresh weight ranged from 302.4 to $467.5 \mathrm{~g}$, which is in the range of the Brazilian market. The pulp thickness was $2.35 \mathrm{~cm}$, which is a feature of great economic interest. The pulp thickness showed close relation with climatic factors, and great variations of temperature and precipitation accelerated the pulp loss of thickness.
\end{abstract}

Key words: Carica papaya L., breeding, fruit quality

1 Parte do Projeto de Iniciação Científica - PIBIC/CNPq/UFES. Bióloga, MSc. Biologia Vegetal, Universidade Federal do Espírito Santo; Doutoranda em Fisiologia Vegetal, Universidade Federal de Viçosa. E-mail: marielamtts@yahoo.com.br;

2 Bióloga, MSc. Biologia Vegetal, Universidade Federal do Espírito Santo; Doutoranda em Ciências dos Alimentos, Universidade de São Paulo. E-mail: sabroetto@yahoo.com.br

3 Bióloga, MSc. Biologia Vegetal, Universidade Federal do Espírito Santo. E-mail: sigridcosta@gmail.com;

$4 \mathrm{Eng}^{\mathrm{o}} \mathrm{Agr}^{\circ}$, DSc. Fitotecnia, Pesquisador do Instituto Capixaba de Pesquisa, Assistência Técnica e Extensão Rural (INCAPER), Docente do PPGBV/UFES. E-mail: adelaide@incaper.es.gov.br

5 Prof. Associado. Depto de Ciências Biológicas/Programa de Pós-Graduação em Biologia Vegetal - Universidade Federal do Espírito Santo, DSc. Fisiologia Vegetal, E-mail: biovegetal@terra.com.br.

* Autor para correspondência. 


\section{Introdução}

Acultura do mamoeiro possui grande importância econômica, especialmente devido ao potencial aumento de demanda no mercado internacional. O mamoeiro (Carica papaya L.) é cultivado em grande parte do território nacional, com destaque para os estados da Bahia, Espírito Santo e Paraíba que, perfazem cerca de $90 \%$ da produção nacional de mamão (MEDEIROS; OLIVEIRA, 2007).

O plantio do mamoeiro se torna antieconômico após dois ou três anos, devido à diminuição da produção e da qualidade dos frutos, ocasionando necessidade de renovação do pomar. Isso gera uma grande demanda por sementes ou mudas, sendo imprescindível a aquisição destes materiais de produtores especializados, que obedeçam a determinados critérios para seleção de plantas matrizes.

Uma vez que a propagação do mamoeiro é feita quase que exclusivamente via sementes, os tipos resultantes são dos mais variáveis, visto que a planta apresenta fácil cruzamento natural. Estimase que no Brasil sejam utilizadas anualmente cerca de $5.000 \mathrm{~kg}$ de sementes de mamão, e que este segmento represente mais de US\$ 4 milhões. Em função dos altos preços praticados no mercado, muitos produtores optam por produzir suas próprias sementes, contribuindo, com isso, para que sejam multiplicados e disseminados materiais genéticos de baixo padrão de qualidade (ALVES; PAVOCA; GALVEAS, 2003).

Em busca da melhoria e obtenção de plantas com características desejáveis, técnicas como a seleção massal são vias de produção de sementes em curto prazo. Esse método consiste na seleção de grande número de indivíduos com características fenotípicas semelhantes, que são colhidas em conjunto para constituir a geração seguinte, melhorando o nível geral da população. As principais vantagens desse método são a facilidade de condução e o baixo custo operacional (BORÉM, 1997).
A cultivar Golden, um importante genótipo com grande aceitabilidade externa, é proveniente de seleção massal realizada em campos de produção de Sunrise Solo na empresa Caliman Agrícola Ltda. no Estado do Espírito Santo, o que mostra a importância de tal prática (COSTA; PAVOCA, 2003).

Entretanto, a produção de sementes descontrolada pode acarretar em perda de identidade dos genótipos como os cultivares selecionados pelos produtores no Espírito Santo, como 'Caliman', 'Baixinho de Santa Amália', 'Golden' e as variações dentro do cultivar Improved Sunrise Solo 72/12, já difundidas em todas as regiões do País, que não apresentam mais suas formas originais definidas (ALVES; PAVOCA; GALVEAS, 2003).

Existe uma carência de informações referentes ao crescimento vegetativo do mamoeiro e as relações entre essa fase e o padrão de qualidade dos frutos, principalmente no que se refere a plantas originadas de sementes selecionadas pelos produtores. Características fenotípicas, como altura das plantas, diâmetro do caule e número de folhas, são importantes indicativos tanto do desenvolvimento da lavoura, como da incidência de distúrbios como a mancha fisiológica.

Yamanishi et al. (2006), trabalhando com duas cultivares de mamoeiro, mostraram a grande utilidade dessas características na avaliação do comportamento do mamoeiro no oeste da Bahia. Da mesma forma, estudos referentes ao desenvolvimento dos frutos constituem outro aspecto de grande importância para a implantação de estratégias de colheita e pós-colheita, aumentando a vida útil e visando um melhor aproveitamento do potencial de comercialização do fruto (GURJÃO et al., 2006).

Devido à grande suscetibilidade do mamoeiro aos fatores climáticos, estudos referentes à relação qualidade do fruto versus clima são de fundamental importância. Silva et al. (2005) mostraram que a temperatura e a pluviosidade têm grande atuação sobre o mamoeiro, influenciando sobre a perda de firmeza da polpa dos frutos. Além disso, alguns 
autores vêm relatando as conseqüências decorrentes das diferentes épocas de desenvolvimento de frutos de mamão, os quais têm as características de qualidade alteradas de acordo com as condições edafoclimáticas de desenvolvimento dos frutos (BERILLI et al., 2007). Por isso, faz-se necessário avaliar o crescimento de plantas do mamoeiro obtidas por seleção massal e sua relação com o padrão de qualidade dos frutos.

Neste contexto, o presente trabalho objetivou monitorar características da pré e da pós-colheita de plantas de mamoeiro, obtidas por seleção massal a partir de plantas da cultivar Golden, visando avaliar o padrão de qualidade dos frutos dos primeiros meses de produção.

\section{Material e métodos}

Sementes provindas de plantas de mamoeiro (Carica papaya L.) cv. Golden, obtidas via seleção massal realizada pelo produtor a partir de plantas matrizes, baseada nas boas características de altura das plantas, diâmetro do caule, número de folhas e quantidade de frutos por planta, foram germinadas em sacos de polietileno pretos (23 x $12 \mathrm{~cm})$, preenchidos com substrato constituído de terra arenosa e esterco de curral curtido, na proporção de 3:1 e mantidas sob ripado. Após aproximadamente 45 dias de emergência, quando atingiram a altura de $20 \mathrm{~cm}$, as mudas foram transferidas para a área de cultivo (Fazenda Herzok) onde foram realizadas as análises. A lavoura localizava-se no município de Aracruz - ES, Latitude $19^{\circ}$ 24"(S), Longitude $40^{\circ} 04 "(\mathrm{~W})$, onde a temperatura média máxima é de $30^{\circ} \mathrm{C} \pm 2$ e a mínima é de $15^{\circ} \mathrm{C} \pm 2$ (FEITOSA, 1986), com precipitação média de $1.183 \mathrm{~mm}^{2} \mathrm{ano}^{-1}$ (CASTRO; SCARDUA, 1985). O plantio foi efetuado em fileiras duplas com espaçamento de 3,6 $\mathrm{m}$ entre linhas e 2,0 m entre plantas, sendo plantadas três mudas por cova (dimensões de 50 × 30 × 30 $\mathrm{cm})$. O solo foi caracterizado como do tipo arenoso, com matéria orgânica variando de 1,5 à 2,6 dag. $\mathrm{kg}^{-1}$ durante o período de estudo.
As plantas foram acompanhadas desde o transplantio das mudas até a colheita dos primeiros frutos, período compreendido de outubro de 2005 a outubro de 2006. A região norte do Estado do Espírito Santo caracteriza-se por possuir um período chuvoso (meses quentes) e período seco (meses frios). O desbaste foi efetuado após a sexagem das plantas aos quatro meses do transplantio, permanecendo apenas uma planta hermafrodita por cova. Utilizou-se o sistema de irrigação por micro-aspersão. Os dados meteorológicos durante a execução do trabalho foram coletados da estação meteorológica do INMET no Instituto Capixaba de Pesquisa, Assistência Técnica e Extensão Rural Linhares-ES (INCAPER).

O crescimento das plantas foi avaliado mensalmente com início logo após o transplantio. As amostragens foram realizadas aos 0, 20, 40, 70, 130, 180, 230, 260, 280, 310 e 340 DAP (dias após o transplantio), perfazendo 11 épocas de amostragem. A cada amostragem, 20 plantas foram selecionadas casualizadamente dentro da lavoura nas quais foram realizadas medições da altura, diâmetro do caule, número de folhas e razão altura/número folhas. Ao início do estádio reprodutivo, aos 130 DAP, foram adicionadas a essas variáveis as análises de número de flores, altura da primeira floração e número de frutos por planta.

Quando os frutos alcançaram o estádio de colheita, dos 230 aos 340 DAP, 70 frutos foram colhidos aleatoriamente dentro da lavoura a cada época de amostragem, correspondendo as análises dos meses de junho a outubro de 2006, e levados para o Laboratório de Ecofisiologia Vegetal da Universidade Federal do Espírito Santo (UFES). Dentre estes, cinco frutos foram avaliados por dia pós-colheita (DAC) do primeiro ao décimo DAC, cada um deste constituindo uma unidade experimental. As variáveis analisadas foram: massa fresca $(\mathrm{g})$, diâmetro $(\mathrm{cm})$, comprimento $(\mathrm{cm}) \mathrm{e}$ espessura da polpa $(\mathrm{cm})$. A firmeza dos frutos foi obtida removendo-se a casca do fruto na região equatorial em seis pontos eqüidistantes, e medida 
utilizando-se um penetrômetro marca EFFEGI. Os resultados correspondentes à média das seis medições foram expressos em $\mathrm{kgf}^{-2}$ usando a fórmula: $\mathrm{P}=\mathrm{F} / \mathrm{A}$, onde $\mathrm{P}$ corresponde à firmeza da polpa $\left(\mathrm{kgf} \mathrm{cm}^{-2}\right), \mathrm{F}$ à força de penetração $(\mathrm{N})$ e $\mathrm{A}$ à área da ponteira $\left(\mathrm{cm}^{2}\right)$, seguindo descrição de Souza (1998).

O delineamento experimental foi inteiramente casualizado, com 11 épocas de amostragem (de 0 a 340 DAP) e 20 repetições por amostragem para as medidas de crescimento das plantas. As análises de pós-colheita dos frutos foram constituídas de cinco épocas de amostragem (230 a 340 DAP) e cinco repetições por dia após colheita. Todos os dados obtidos foram submetidos a análise de variância, e, quando os valores de $\mathrm{F}$ foram significativos, uma comparação de médias foi realizada, usando-se o teste DUNCAN a 5\% de probabilidade.

\section{Resultados e discussão}

As plantas analisadas apresentaram curva de crescimento em altura tipicamente sigmóide (Figura 1A), apresentando aos 130 DAP, ao início da produção dos frutos, alturas de $125 \mathrm{~cm}$, menores que os $190 \mathrm{~cm}$ observados em plantas de Golden aos 160 DAP (SILVA, 2009), alcançando aos 340 DAP cerca de $200 \mathrm{~cm}$. A altura observada nestas plantas, menor que para o mamoeiro do grupo Solo (COSTA; PAVOCA, 2003), constitui uma interessante característica quando se considera o crescimento em altura como um dos maiores problemas no campo, pois pode dificultar o alcance dos frutos para a colheita.

O diâmetro do caule também apresentou curva de crescimento sigmóide, apresentando crescimento seguido de estabilização após 230 DAP e valores próximos a $11,80 \mathrm{~cm}$ até o final do experimento (Figura 1B).

Houve grande variação no número de folhas (Figura 1C), com aumento linear até o $40^{\circ}$ DAP e chegando a valores superiores a 35 folhas por planta, seguida de redução até o 260 DAP e posterior aumento. O mamoeiro apresenta uma modificação morfológica da transição da fase jovem para a fase adulta, quando ocorre redução do número de folhas, concentrando-as como um grupo denso de grandes folhas na região apical e passando a se apresentarem de forma espiralada - fato comprovado quando se analisa a razão altura/número de folhas (Figura 1D).

Esse índice apresentou um aumento progressivo, mostrando seus maiores valores principalmente na fase de colheita - essa interessante variável indica a eficiência no recobrimento foliar das plantas. A menor altura, juntamente com a maior área foliar (favorecida pelo maior número de folhas), oferece maior sombreamento aos frutos, impedindo a incidência solar direta e diminuindo a probabilidade de ocorrência de desordens fisiológicas.

A altura da primeira floração variou entre 50 e $80 \mathrm{~cm}$, com média de $70 \mathrm{~cm}$, com plantas precoces (início da produção dos frutos a 130 DAP) e colheita a 230 DAP. Segundo Costa e Pavoca (2003), a precocidade do estádio reprodutivo está diretamente associada à altura das primeiras florações e, conseqüentemente, à produtividade. Esses resultados corroboram Dantas e Lima (2001), que observaram em linhagens de híbridos dos Grupos Solo e Formosa a ocorrência de redução da altura da inserção da primeira flor (altura do primeiro fruto) do híbrido em relação aos parentais. Os autores afirmam que este fato tem grande importância econômica porque permite uma maior longevidade de colheita e, conseqüentemente, uma maior produção por planta, permitindo a exploração de ciclos mais avançados do mamoeiro. Assim, a obtenção de plantas com os primeiros frutos mais baixos e maior área de recobrimento facilitará o processo de colheita durante períodos mais prolongados, mostrando a importância da seleção de indivíduos fenotipicamente superiores para a obtenção de híbridos com características comercialmente favoráveis, uma vez que baixa posição de frutos e precocidade geralmente são hereditários, portanto, transmissível. 


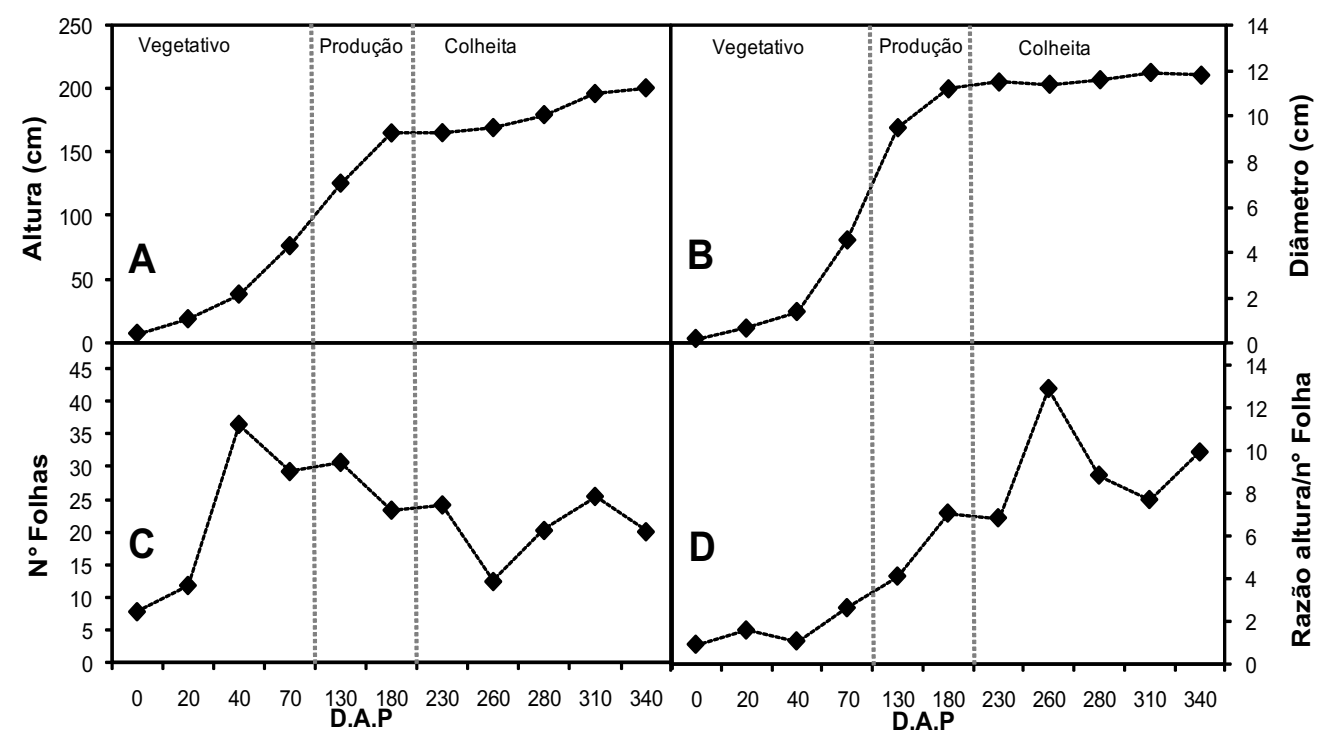

Figura 1. Parâmetros biométricos do mamoeiro (Carica papaya L.): altura da planta (A), diâmetro do caule (B) e número de folhas $(\mathrm{C})$, em função dos dias após o transplantio. Amostragem 0 corresponde à semana do plantio $(\mathrm{n}=20)$.

Variáveis como a razão altura/número de folhas, maior número de folhas e diâmetro de caule, poderiam indicar o status de vitalidade das plantas; e, segundo Ueno et al. (2002), plantas de mamoeiro mais vigorosas, com maior enfolhamento e tronco com maior diâmetro dentro de uma mesma área, apresentaram menor intensidade de mancha fisiológica.

$\mathrm{O}$ número de frutos (Figura 2) apresentou aumento progressivo até os 280 DAP, alcançando cerca de 60 frutos/planta durante a fase de colheita, seguida de redução para cerca de 40 frutos por planta. Segundo Simão (1971) apud Yamanishi et al. (2006), a produção do primeiro ano varia de 40 a 60 frutos por planta, categorizando essa lavoura como de alta produtividade. Entretanto, Marin et al. (1995) afirmam que uma planta com boa capacidade produtiva é aquela que, após nove meses de plantio, produz número de frutos igual ou superior a 70 frutos por planta, o que resultaria na classificação desta lavoura aos 280 DAP (nove meses de plantio) como de produção média.

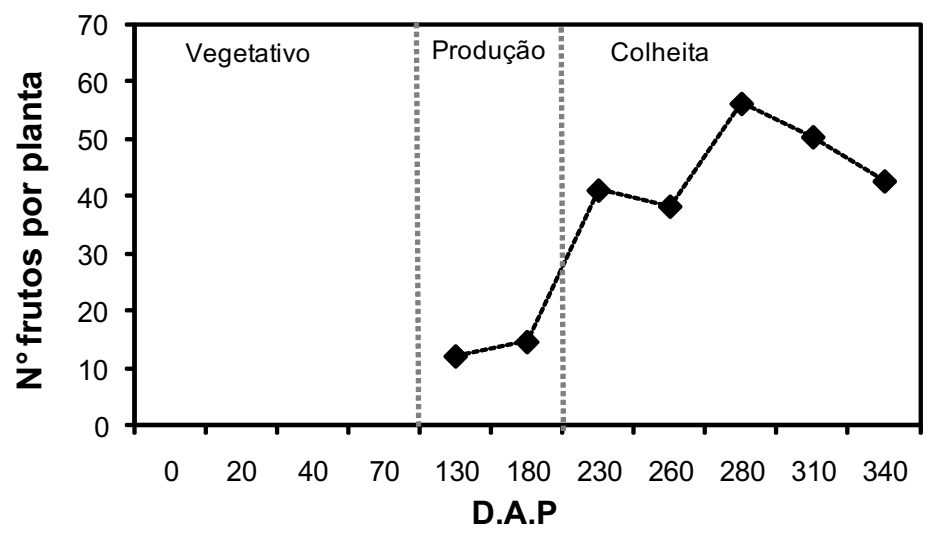

Figura 2. Índices de produtividade do mamoeiro (Carica papaya L.) em função dos dias após o transplantio. Amostragem 0 corresponde à semana do plantio. $(n=20)$ 
Os frutos obtidos mantiveram características desejáveis da cultivar 'Golden', ou seja, frutos hermafroditas de formato piriforme, coloração da polpa rosa-salmão, casca lisa e cavidade estrelada. Os resultados das análises físicas dos frutos dos primeiros meses de produção da lavoura estão representados na Tabela 1. O peso dos frutos variou de 302,4 a 467,5g, com diâmetro entre 7,44 e 8,77, e média de $8,43 \mathrm{~cm}$, apresentando espessura da polpa com valores médios acima de $2 \mathrm{~cm}$.

$\mathrm{O}$ peso dos frutos analisados encontrava-se de acordo com a classificação do Programa Brasileiro para a Modernização da Horticultura (CQH/
CEAGESP, 2003), correspondendo também à preferência do mercado interno (SOUZA, 1998); enquanto o diâmetro dos frutos analisados foi maior ao encontrado por Soprani et al. (2004) para a cultivar Golden. A espessura média está de acordo com Yamanishi et al. (2006), que afirmam que espessura média acima de $20 \mathrm{~mm}$ é considerada de valor ideal para comercialização. Assim, a maior espessura encontrada constitui um atributo de grande interesse econômico, uma vez que é atraente ao consumidor e possibilita maior proteção contra choque mecânico.

Tabela 1. Massa Fresca (g), Comprimento $(\mathrm{cm})$, Diâmetro $(\mathrm{cm})$ Espessura da polpa $(\mathrm{cm})$ e Porcentagem de massa seca na polpa de frutos do mamoeiro Carica papaya L. cultivados em uma lavoura comercial do município de Aracruz - ES.

\begin{tabular}{lccccc}
\hline & $\begin{array}{c}\text { Massa Fresca } \\
(\mathbf{g})\end{array}$ & $\begin{array}{c}\text { Comprimento } \\
(\mathbf{c m})\end{array}$ & $\begin{array}{c}\text { Diâmetro } \\
(\mathbf{c m})\end{array}$ & $\begin{array}{c}\text { Espessura } \\
\text { polpa }(\mathbf{c m})\end{array}$ & $\begin{array}{c}\text { Massa Seca } \\
(\%)\end{array}$ \\
\hline Junho & $302,4 \mathrm{~b}$ & $12,48 \mathrm{NS}$ & $7,44 \mathrm{~b}$ & $2,17 \mathrm{~b}$ & $11,81 \% \mathrm{a}$ \\
Julho & $436,0 \mathrm{a}$ & 12,28 & $8,58 \mathrm{a}$ & $2,31 \mathrm{ab}$ & $9,21 \% \mathrm{~b}$ \\
Agosto & $462,6 \mathrm{a}$ & 12,61 & $8,65 \mathrm{a}$ & $2,43 \mathrm{a}$ & $11,31 \% \mathrm{a}$ \\
Setembro & $467,5 \mathrm{a}$ & 12,50 & $8,70 \mathrm{a}$ & $2,43 \mathrm{a}$ & $11,68 \% \mathrm{a}$ \\
Outubro & $453,5 \mathrm{a}$ & 11,98 & $8,77 \mathrm{a}$ & $2,41 \mathrm{a}$ & $12,32 \% \mathrm{a}$ \\
\hline Média & 424,4 & 12,37 & 8,43 & 2,35 & $11,26 \%$ \\
\hline
\end{tabular}

Médias com letras diferentes nas colunas indicam diferença significativa em nível de $5 \%$ de probabilidade pelo teste de DUNCAN. $n s=$ não significativo. $(\mathrm{n}=5)$.

As menores dimensões dos frutos foram observadas no mês de junho, enquanto nos demais meses o tamanho do fruto manteve-se semelhante aos da cultivar Golden. Considerando-se que a formação do fruto do mamoeiro é de 145 dias (CALEGARIO, 1999), os frutos da primeira colheita (mês de junho) tiveram, durante sua formação, a influência das variações ocorridas em fevereiro de 2006 - mês que se destacou por elevadas temperaturas médias e que, embora ocasionasse também a elevação da temperatura mínima, teve amplitude térmica maior de todo o período de estudo (Figura 3). As menores dimensões provavelmente estariam relacionadas às extremas elevações de temperatura ocorridas neste mês, resultando na aceleração do desenvolvimento do fruto e ocasionando o precoce alcance da maturação e fazendo-os atingir seu estágio de colheita em menor tempo. Berilli et al. (2007) relacionaram o crescimento e desenvolvimento do fruto do mamoeiro com a temperatura. Estes autores observaram que temperaturas mensais mais elevadas aceleram o desenvolvimento dos frutos, reduzindo bastante a fase de maturação dos mesmos. Os autores também sugerem que períodos mais quentes durante a fase de desenvolvimento dos frutos favorecem a ocorrência de frutos com maiores comprimentos e com diâmetros menores. 


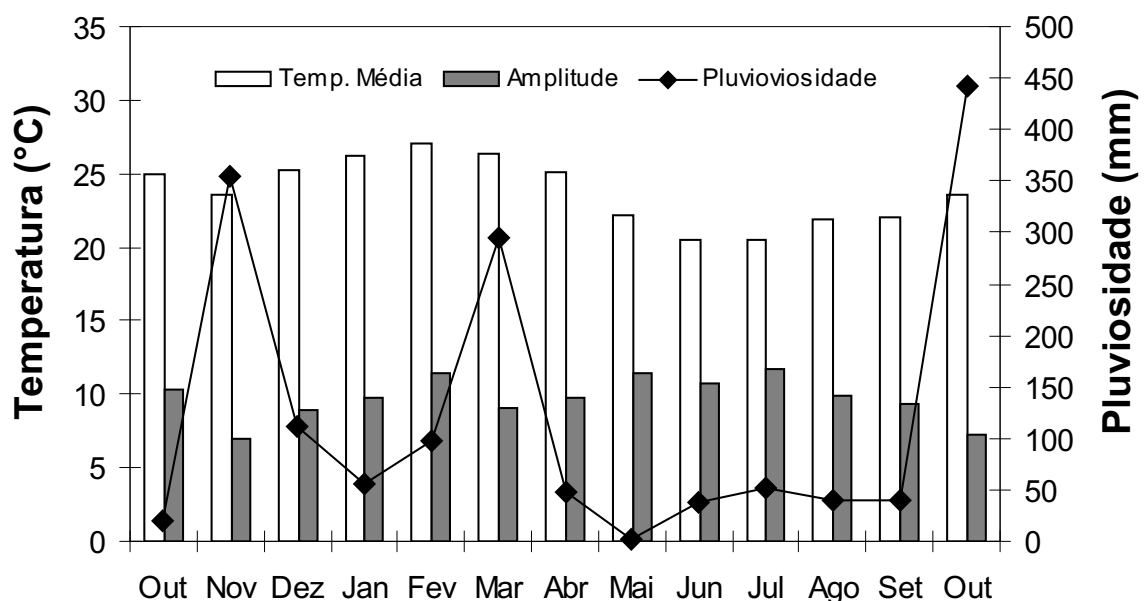

Figura 3. Temperatura média, amplitude térmica e pluviosidade, no Município de Aracruz no período de outubro de 2005 a outubro de 2006 (Dados INCAPER).

No presente trabalho, embora o ponto de colheita tenha sido alcançado antecipadamente, as temperaturas elevadas e a amplitude térmica favoreceram a maturação dos frutos em detrimento do aumento do tamanho. A firmeza da polpa dos frutos no mês de junho confirma sua acelerada maturação (Figura 4), pois já no terceiro dia após colheita, apresentaram valores menores que 3 kgf. $\mathrm{cm}^{-2}$, que corresponde ao fruto totalmente maduro, dificultando seu manuseio no comércio e conservação. A firmeza da polpa dos demais meses analisados apresentou, por outro lado, diferentes comportamentos: em julho e agosto, ao considerar um tempo de formação de 145 dias, tiveram seu desenvolvimento ocorrido durante o período chuvoso (elevadas temperaturas), apresentaram maior tempo de manutenção da firmeza - ou seja, esses frutos mantiveram sua firmeza por maior período de tempo. Por outro lado, os frutos analisados em setembro e outubro tiveram sua formação ocorrida durante o período de seca (baixas temperaturas), apresentando perda de firmeza da polpa acelerada.

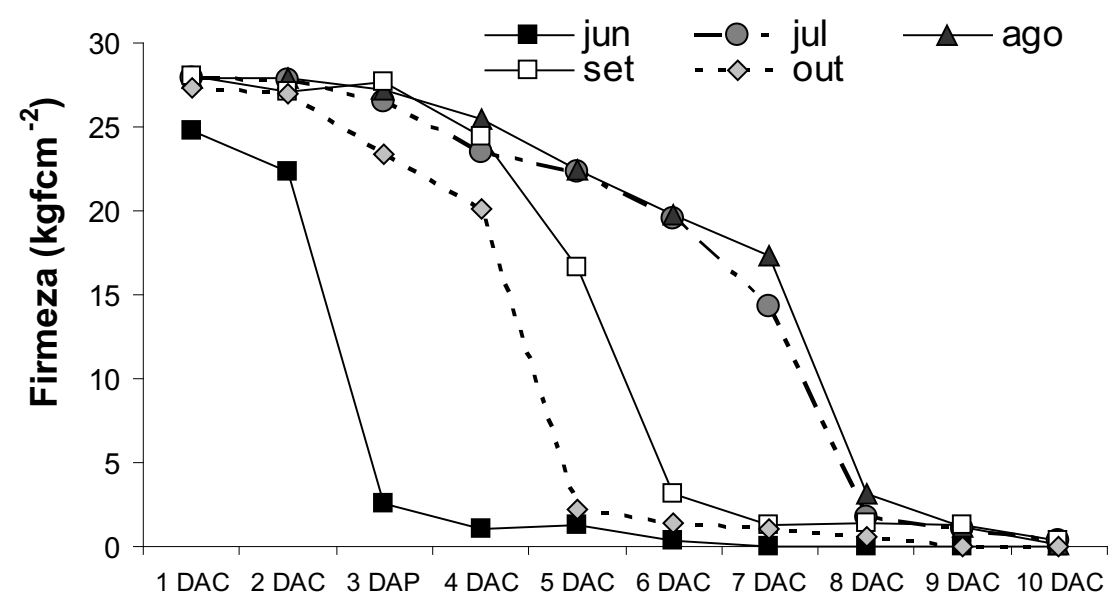

Figura 4. Perda de firmeza da polpa do mamoeiro (Carica papaya L.) cv. Golden em relação aos dias após colheita (D.A.C) avaliados nos meses de junho a outubro de 2006. $(\mathrm{n}=5)$ 
Esses resultados mostram que frutos formados em época de menores temperaturas e pluviosidades apresentam menor vida de prateleira que os formados no período quente e chuvoso. Também levam a supor que as baixas temperaturas e seca afetariam a firmeza da polpa devido ao maior tempo de desenvolvimento dos frutos nesses períodos. Tal fator ocasionaria um prolongamento do tempo de desenvolvimento dos frutos até seu ponto de colheita e aumentaria seu tempo de exposição à estresses como frio e elevadas amplitudes térmicas.

Os resultados mostram, ainda, que as extremas temperaturas constatadas em fevereiro ocasionaram a aceleração do desenvolvimento dos frutos da primeira colheita, favorecendo sua maturação em detrimento do seu desenvolvimento em tamanho e reduzindo o tempo de vida de prateleira. Os frutos formados nos meses de maiores temperaturas e pluviosidades apresentaram menor perda de firmeza, ou seja, maior vida de prateleira; enquanto a formação de frutos em períodos de baixas temperaturas e secas favoreceu a maturação de frutos com acelerada perda de firmeza da polpa e, portanto, menor vida de prateleira.

\section{Conclusões}

As plantas obtidas por seleção massal a partir de plantas da cv. 'Golden' apresentaram características de grande interesse comercial: menor altura das plantas, maior número de frutos por planta, maior área de recobrimento dos frutos devido ao maior número de folhas, e primeira floração mais baixa;

Os frutos apresentaram maior diâmetro e polpa espessa, de maior atratividade ao consumidor.

Houve estreita relação entre a perda de firmeza e as características climáticas da época de formação do fruto: frutos formados durante período frio e seco apresentam menor vida de prateleira.

\section{Agradecimentos}

A realização desta pesquisa foi possibilitada graças ao apoio financeiro do Banco do Nordeste, a doação de frutos e disponibilização da área para a coleta dos dados pela Fazenda Herzog e bolsa de Iniciação Científica do PIBIC/CNPq/UFES.

\section{Referências}

ALVES, F. L.; PAVOCA, B. E. V.; GALVEAS, P. A. O. Seleção de plantas matrizes de mamão, grupo Solo, para produção de sementes. IN: MARTINS, D. S.; COSTA, A. F. S. (Ed.). A cultura do mamoeiro: tecnologias de produção. Vitória, ES: Incaper, 2003, p.105-114.

BERILLI, S. S.; OLIVEIRA, J. G.; MARINHO, A. B.; LYRA, G. B.; DE SOUSA, E. F.; VIANA, A. P.; BERNARDO, S; PEREIRA, M. G. Avaliação da taxa de crescimento de frutos de mamão (Carica papaya L.) em função das épocas do ano e graus-dias acumulados. Revista Brasileira de Fruticultura, Jaboticabal, v. 29, n. 1, p. 11-14, abr. 2007.

BORÉM, A. Melhoramento de plantas. Viçosa, MG: UFV, 1997. $547 \mathrm{p}$.

CALEGARIO, F. F. Características físicas e químicas do fruto do mamão (Carica papaya L.) em desenvolvimento. 1999. In: SILVA, J. G. F. Efeitos de diferentes lâminas e freqüencias de irrigação sobre o desenvolvimento e produtividade do mamoeiro (Carica papaya L.). 1999. 90 f. Tese (Doutorado em Engenharia Agrícola). Departamento de Engenharia Agrícola - Universidade Federal de Viçosa. Viçosa, MG:

CASTRO, L. L. F.; SCARDUA, J. A. Estimativa da necessidade potencial de irrigação para o Estado do Espírito Santo. Cariacica: EMCAPA, 1985, p. 87 (Documentos, n. 22).

COSTA, A. F. S.; PAVOCA, B. E. V. Caracterização de cultivares, estratégias e perspectivas de melhoramento genético do mameiro. In: MARTINS, D. S.; COSTA, A. F. S. (Ed.). A cultura do mamoeiro: tecnologias de produção. Vitória, ES: Incaper, 2003, p. 58-102.

CENTRO DE QUALIDADE EM HORTICULTURA. Programa Brasileiro para a Modernização da Horticultura. Normas de classificação do mamão. Centro de qualidade em horticultura. São Paulo: CQH/CEAGESP. 2003. (Documentos, n. 25). 
DANTAS, J. L. L.; LIMA, J. F. D. Seleção e recomendação de variedades de mamoeiro - avaliação de linhagens e híbridos. Revista Brasileira de Fruticultura, Jaboticabal, v. 23, n. 3, p. 617-621, jul. 2001.

FEITOSA, L. R. Carta agroclimática do Espírito Santo. Vitória, ES: Governo do Estado, SEAG, EMCAPA, 1986. mapa, color. Escala: 1:400.000.

GURJÃO, K. O.; BRUNO, R. A.; ALMEIDA, F. C.; PEREIRA, W. E.; BRUNO, G. B. Desenvolvimento de frutos e sementes de tamarindo. Revista Brasileira de Fruticultura, Jaboticabal, v. 28, n. 3, p. 351-354, jul. 2006.

MARIN, S. L. D.; GOMES, J. A.; SALGADO, J. S.; MARTINS, D. S.; FULLIN, E. A. Recomendações para a cultura do mamoeiro dos grupos solo e formosa no Estado do Espírito Santo. 4. ed. rev. ampl., Vitória: EMCAPA, 1995. 57 p. (Circular Técnica, 3).

MEDEIROS, J. F.; OLIVEIRA, F. A. D. Fertirrigação da cultura do mamoeiro. IN: MARTINS, D.; COSTA, A. N.; COSTA, A. F. S. (Ed.). Papaya Brasil: manejo, qualidade e mercado do mamão. Vitória, ES: Incaper, 2007. 704 p.

SILVA, M. M. Alterações fisiológicas e nutricionais durante as fases do desenvolvimento vegetativo $e$ reprodutivo do mamoeiro Golden. 2009. 83 f. Dissertação (Mestrado em Biologia Vegetal). Departamento de Ciências Biológicas - Universidade Federal do Espírito Santo, Espírito Santo.

SILVA, M. M.; BROETTO, S. G.; FONTES, R. V.; BALBINO, J. M.; SILVA, D. M. Influência dos fatores pré-colheita na perda de firmeza em frutos do mamoeiro (Carica papaya L.) cv. Golden e Gran Golden. In: MARTINS, D. S. (Ed.). Papaya Brasil: mercado e inovações tecnológicas para o mamão. Vitória: DCM Incaper. 2005. p. 568-571.

SOPRANI, J.; FERRAZ, K. F; SILVA, D. M.; FIGUEIREDO, S. G. Características físicas e evolução dos teores de açúcares durante o amadurecimento do mamão. In: CONGRESSO BRASILEIRO DE FRUTICULTURA, 18., 2004, Florianópolis. Anais... Florianópolis: Editora, 2004. p. 1. CD-ROM.

SOUZA, G. Características fisicas, químicas e sensoriais do fruto de cinco cultivares de mamoeiro produzidas em Macaé, RJ. 1998, 87 f. Dissertação (Mestrado em Tecnologia). Centro de Ciências e Tecnologia Agropecuária (CCTA) - Universidade Estadual do Norte Fluminense, Rio de Janeiro.

UENO, B.; CAMPOSTRINI, E.; NEVES, E. F.; FAGUNDES, G. R.; MACHADO FILHO, J. A.; YAMANISHI, O. K. Estudos sobre métodos de manejo da mancha fisiológica em frutos de mamoeiro (Carica papaya L.) no oeste da Bahia. Brasília: Setor de Fruticultura da Faculdade de Agronomia e Medicina Veterinária da Universidade de Brasília, 2002. 109 p. (Documento, n. 4).

YAMANISHI, O. K.; MELLO, R. M.; MARTINS, V. A.; LIMA, L. A.; FAGUNDES, G. R. Comportamento do mamoeiro Sekati nas condições do oeste da Bahia. Revista Brasileira de Fruticultura, Jaboticabal, v. 28, n.1, p. 79-82, jan. 2006. 
